\title{
A PESQUISA-AÇÃO EM EDUCAÇÃO AMBIENTAL: UMA EXPERIÊNCIA NO ENTORNO DE UMA UNIDADE DE CONSERVAÇÃO URBANA
}

\section{Action-research in environmental education: an experience in the surroundings of an urban protected area}

\author{
Tania Maria Cerati ${ }^{1}$ \\ Rosmari Aparecida de Morais Lazarini ${ }^{2}$
}

\begin{abstract}
Resumo: O Parque Estadual das Fontes do Ipiranga (PEFI), localizado no município de São Paulo, sofre inúmeros impactos ambientais que comprometem a conservação deste importante remanescente de Mata Atlântica. O presente trabalho apresenta a construção de um projeto de Educação Ambiental utilizando a metodologia da pesquisa-ação que teve como objetivo sensibilizar a comunidade do entorno sobre a importância da conservação dessa área. Desenvolvido em uma escola pública, contou com a participação de 29 professores e novecentos alunos. Os resultados mostram que, por meio da socialização do conhecimento científico, foram inseridas, no cotidiano escolar, discussões sobre a importância da manutenção do PEFI, o que contribuiu não só para o desenvolvimento socioambiental da comunidade, como também para a melhoria da qualidade do ensino.
\end{abstract}

Palavras-chave: Educação Ambiental. Pesquisa-ação. Unidades de conservação. Capacitação de professores.

\begin{abstract}
The Parque Estadual das Fontes do Ipiranga (PEFI), which is a park located in the city of São Paulo, has suffered countless environmental impacts that have compromised the conservation of this important remaining Mata Atlântica (Atlantic Rain Forest). This paper is about the creation of an environmental education project that uses action-research methodology, which focuses on raising public awareness of the surroundings and the importance of protecting such an area. Developed in a public school, 29 teachers and 900 students participated in the project. The results show that through the socialization of scientific knowledge and discussions about the importance of PEFI maintenance/ protection, which were introduced into day-to-day school life, the program has contributed not only to the community's social-environmental development, but also to the improvement in teaching quality.
\end{abstract}

Keywords: Environmental education. Action-research. Protected areas. Teachers' training.

\footnotetext{
${ }^{1}$ Pesquisadora científica. Instituto de Botânica, Secretaria Estadual do Meio Ambiente. Agência de fomento: BGCI - Botanic Gardens Conservation International. Instituto de Botânica. São Paulo, SP.

$<$ tcerati_ibt@yahoo.com.br>

${ }^{2}$ Bióloga, Especialista em Meio Ambiente. Agência de fomento: BGCI. Instituto de Botânica. São Paulo, SP

<rosmari_lazarini@yahoo.com.br>

${ }^{1}$ Av. Miguel Stefano, n. 3687

São Paulo, SP

04.301-012

383

Ciência \&̊ Educação, v. 15, n. 2, p. 383-92, 2009
} 
O bioma Mata Atlântica, em virtude de sua elevada biodiversidade, é considerado área prioritária de conservação dentro do conceito de Hotspots. Este bioma cedeu espaço para o estabelecimento das grandes cidades brasileiras, entre elas a Região Metropolitana de São Paulo, que ocupa, aproximadamente, uma extensão menor que $0,1 \%$ da superfície do Brasil e abriga mais de $10 \%$ de sua população, constituindo hoje uma das maiores aglomerações urbanas do planeta (SÃO PAULO, 2002).

Inserido nos domínios da Mata Atlântica e cercado pela malha urbana paulista, está o Parque Estadual das Fontes do Ipiranga (PEFI). Com 526 ha de área, possui uma Reserva Biológica que abriga elevada riqueza de espécies fanerogâmicas, com 129 famílias, 543 gêneros e 1.159 espécies, sendo que 36 desses táxons encontram-se ameaçados de extinção. Na área do PEFI localizam-se também dois importantes aquíferos subterrâneos e 24 nascentes, três das quais formam o histórico Riacho do Ipiranga (BICUDO, FORTI e BICUDO, 2002). O Parque configura-se também como um patrimônio cultural, uma vez que nessa região importantes acontecimentos históricos foram registrados.

Localizado no PEFI, está o Jardim Botânico de São Paulo (JBSP). Fundado em 1928, é o mais antigo do Estado e tem como missão a conservação da biodiversidade, pesquisa científica e Educação Ambiental (EA), configurando-se no cenário brasileiro como uma importante instituição científica, produtora de conhecimento. Os jardins botânicos contemporâneos desempenham importante papel na sensibilização e conscientização do público para a preservação do ambiente natural e a melhoria da qualidade de vida no meio urbano. Para tanto, desenvolvem-se programas que promovem o entendimento e divulgam o conhecimento sobre a biodiversidade e as consequências de sua perda. Esses programas abrangem moradores do entorno e a população em geral, contribuindo, também, para o estabelecimento de políticas públicas municipais, estaduais ou federais (PEREIRA, COSTA e JACKSON, 2004). A Educação Ambiental está incorporada em todas as principais estratégias internacionais para a conservação da biodiversidade. Os 1.600 jardins botânicos existentes no mundo unem esforços para a implementação dessas estratégias, uma vez que, juntos, mantêm a maior coleção de espécies vegetais fora da natureza. Estima-se que cerca de 60.000 espécies vegetais estão ameaçadas de extinção, e os jardins botânicos têm importância vital na preservação dessas espécies. Porém nenhum projeto de conservação de biodiversidade terá êxito sem a participação da Educação Ambiental (WILLISON, 2003).

Mas como proteger este fragmento de Mata Atlântica que se localiza na periferia da cidade de São Paulo, área densamente urbanizada e com alta taxa populacional? Os efeitos dessa urbanização foram relatados por Reis (2002), que constatou a presença de diversos tipos de resíduos sólidos no entorno do Parque, sendo o lixo e o esgoto doméstico os principais agentes impactantes da vegetação, do solo e água das nascentes.

Sensibilizar e despertar a consciência crítica de grupos sociais no entorno das Unidades de Conservação (UCs) e estimular a participação da comunidade na proteção dos recursos naturais, têm sido consideradas as ações mais adequadas para a efetiva proteção dessas áreas (MAROTI, 2002; TABANEZ, PÁDUA e SOUZA, 1997). Essa consciência crítica é despertada por meio da Educação Ambiental, que tem como desafio promover a mudança de valores, posturas e atitudes, sendo necessário integrar suas ações aos aspectos ecológicos, políticos, culturais e éticos. 
A pesquisa-ação em educação ambiental...

De acordo com Silva e Junqueira (2007), para estimular a percepção das pessoas direta ou indiretamente envolvidas no processo de conservação de áreas naturais e das espécies nela abrigadas, é imprescindível ter como mediadores os educadores ambientais, que são o elo entre a ciência e conservação ambiental, onde a participação das populações envolvidas é fundamental. Essa mediação é complexa e o educador ambiental não pode esquecer que seu trabalho deve estar embasado nos princípios da Educação Ambiental: participação, pensamento crítico-reflexivo, sustentabilidade, ecologia de saberes, responsabilidade, continuidade, igualdade, conscientização, coletividade, emancipação e transformação social, sem esquecer o cunho político (GONZALES, TOZONI-REIS e DINIZ, 2007).

Este estudo parte do princípio de que os jardins botânicos são importantes espaços geradores de conhecimento científico, que devem ser socializados para promover reflexões sobre o meio ambiente buscando conscientizar a população sobre a importância da conservação da biodiversidade.

Assim, a equipe de Educação Ambiental do Jardim Botânico de São Paulo, percebendo a necessidade de estabelecer uma relação com a comunidade do entorno, "aceitou" o desafio de desenvolver um projeto para promover a construção dessa relação. Escolheu, então, atuar em uma escola pública, porque: é um espaço tradicionalmente indicado para a discussão e aprendizado de temas atuais e urgentes; acolhe a realidade sociocultural de sua comunidade com a vocação de testemunhar seus sonhos, anseios, conflitos, desejos e esperanças; incentiva ações, reações, compromissos, devendo envolver-se na dinâmica social. Todos esses fatores favorecem a implantação de um projeto de Educação Ambiental onde a problemática ambiental local possa ser debatida com a comunidade.

Portanto, o presente trabalho mostra a construção e os resultados desse projeto, que teve como objetivo estabelecer um canal de comunicação entre os pesquisadores do Jardim Botânico e uma escola do entorno, buscando sensibilizar alunos, professores e a comunidade em geral sobre a importância da preservação da mata do PEFI por meio do compartilhamento dos saberes.

O projeto foi desenvolvido no período de agosto a dezembro de 2005, na E.E "Valentim Gentil" de Ensino Fundamental I, que se caracteriza como uma escola aberta a projetos inovadores e com importante papel social na região. Possui 29 salas de aula, corpo docente formado por 29 professores e discente com novecentos alunos. Localizada a novecentos metros do Jardim Botânico, atende a comunidade que tem hábito observar a mata sem, no entanto, saber sua importância, o que ela abriga e os benefícios ambientais que proporciona para a população. Tanto a escola quanto o Jardim Botânico localizam-se no bairro Água Funda, que surgiu em 1880 e recebe esse nome, provavelmente, pelo elevado número de nascentes encontradas na região. Nas últimas décadas, o bairro sofreu crescente progresso em quase todos os setores, desencadeando crescimento urbano desordenado, que provoca impactos na vegetação, no solo e nos ambientes aquáticos do Parque e na saúde da população, conforme constatado por Reis (2002). A escolha dessa escola ocorreu pela proximidade, além de seu projeto pedagógico ter, como eixo temático, o meio ambiente, o que facilita a inserção e reflexão sobre temas relacionados à conservação da natureza. 


\section{Metodologia}

Muitos questionamentos surgiram, por exemplo: - Por meio de que processo podemos incorporar a problemática ambiental na escola para gerar reflexões sobre o meio ambiente da região? - Como propiciar situações de reflexões e troca de saberes? - Quais situações poderiam ser realizadas para a construção de um conhecimento sobre o PEFI e JBSP na comunidade escolar? Estes questionamentos nos levaram a optar pela metodologia da pesquisa-ação para nortear os trabalhos.

A pesquisa-ação é definida, por Thiollent (2005), como uma metodologia derivada da pesquisa social com base empírica, concebida e realizada em estreita associação com uma ação ou a resolução de um problema coletivo, e na qual pesquisadores e participantes representativos da situação ou problema estão envolvidos de modo cooperativo ou participativo.

Sato (1997) considera essa metodologia a mais indicada para pesquisas em Educação Ambiental por permitir a participação dos envolvidos por meio de reflexões críticas de um problema percebido por todos, potencializando a emancipação e a participação social. A autora destaca ainda que a pesquisa-ação está sendo amplamente difundida e utilizada nos grandes projetos realizados em diversos países europeus onde professores são estimulados a desenvolver atividades em Educação Ambiental nas suas escolas.

A pesquisa-ação é empregada por De Fiori (2002), Maroti (2002) e Araújo (2006) em trabalhos de Educação Ambiental no entorno de unidades de conservação para sensibilizar a comunidade da importância de manutenção dessas áreas.

De acordo com Tozoni-Reis (2005), a metodologia de pesquisa-ação em Educação Ambiental está centrada em três "práticas" que se articulam entre si: a produção de conhecimento, ação educativa e a participação dos envolvidos, tomando, como ponto de partida, um problema existente e detectado pelas equipes. Nesta pesquisa os participantes deixam de ser objeto de estudos para serem pesquisadores e produtores de conhecimento de sua própria realidade.

A pesquisa-ação tem, como característica principal, a construção coletiva do conhecimento, onde todos têm voz ativa (GONZALES, TOZONI-REIS e DINIZ, 2007).

Assim, de acordo com a fundamentação teórica da pesquisa-ação, estabelecemos as seguintes etapas metodológicas para esta pesquisa: detecção do problema, interação, tema gerador, acompanhamento das decisões e ações; resolução de problema; nível de consciência. Estas etapas são destacadas ao longo do texto.

O processo de pesquisa foi iniciado na escola com a permissão da direção escolar para que os pesquisadores acadêmicos se reunissem, semanalmente, com os professores durante a HTPC (Hora de Trabalho Pedagógico Coletivo). Cabe ressaltar que a HTPC é institucionalizada nas escolas públicas estaduais como um horário para trabalhos pedagógicos destinado à promoção do diálogo, planejamento de atividades, avaliações e reflexões sobre práticas educativas, troca de saberes e experiências entre professores. Para Leme (2006), este espaço representa uma excelente oportunidade para a capacitação dos professores e construção de relações baseadas na reciprocidade, confiança, compreensão, solidariedade, estabelecendo vínculos a uma prática condizentes com os pressupostos de EA.

A coleta de dados foi realizada utilizando-se a técnica de aplicação de questionário, observação participativa e registros fotográficos dos encontros e demais atividades. 
A pesquisa-ação em educação ambiental...

O primeiro encontro iniciou a interação entre os sujeitos da pesquisa; foi realizado em agosto de 2005 quando houve a apresentação da equipe, formada por 29 professores (professores pesquisadores) e três pesquisadores acadêmicos. Os objetivos foram apresentados, afirmando-se que este projeto "não estava pronto", seria construído em conjunto, pela equipe então formada. Portanto, seria um projeto dinâmico, com mudanças de rumo, se necessário, onde todos teriam voz. Os professores, agora parceiros, atuariam na pesquisa utilizando seus talentos, habilidades e experiências frente à situação investigada e empreendendo esforços na elaboração de ações para a busca de soluções, contando com o aporte de conhecimento e experiência advindo dos pesquisadores.

Para avaliar a percepção dos professores em relação ao Jardim Botânico e PEFI, foi aplicado um questionário, cujo resultado demonstrou que $60 \%$ já haviam visitado o Jardim Botânico com os alunos para trabalhar temas relacionados à vegetação e meio ambiente, mas desconheciam o Parque e não tinham informações e conhecimentos suficientes para avaliar sua importância para a região. Os professores conheciam algumas espécies ameaçadas de extinção preservadas no JBSP, como: pau-brasil, araucária e xaxim. Quando questionados sobre os problemas socioambientais da região, os mais citados foram poluição do ar, falta de arborização e jardins públicos, demonstrando que não reconhecem o Jardim Botânico como área verde.

Os pesquisadores acadêmicos observaram a receptividade dos professores às atividades realizadas e a possibilidade de aprimorar sua formação. Mostraram interesse em "aprender mais" sobre o Jardim Botânico, as plantas que ele conserva e a mata, pois, desta forma, poderiam sensibilizar seus alunos e melhorar a qualidade das aulas. Assim, estava estabelecido o tema gerador: "O Jardim Botânico e o PEFI". O tema gerador, de acordo com Gonzáles, Tozoni-Reis e Diniz (2007), deve ser aquele em que a equipe se mobiliza para entendê-lo e, desta forma, compreender a realidade que os cerca, ou seja, não se limita à sua mera compreensão, mas parte dele para compreender a realidade que os cerca com sentido investigativo e educativo. Os professores solicitaram uma palestra sobre o tema gerador como forma de iniciar a discussão e reflexão.

Os pesquisadores organizaram, para o segundo encontro, a palestra intitulada " $\mathrm{O}$ Jardim Botânico de São Paulo e o Parque Estadual das Fontes do Ipiranga na conservação da biodiversidade". Com a participação efetiva de todos, ficou estabelecido que, no próximo encontro, um cronograma de atividades, sugeridas pelos professores, seria elaborado.

No terceiro encontro, uma discussão sobre a palestra mostrou que os professores desconheciam a história, a riqueza vegetal e o valor ambiental do PEFI e JBSP e, reconheceram, ainda, que esta área preservada tão próxima da escola poderia ser utilizada como recurso didático para a produção de conhecimentos ambientais locais. Nesse momento se revelou a defasagem de conhecimento dos professores sobre assuntos relacionados à temática ambiental - eles não se sentiam aptos a discutir alguns temas com os alunos e esperavam dos pesquisadores acadêmicos suporte para suprir essas dificuldades, sugerindo, então, a realização de palestras, aulas práticas e visitas ao Jardim Botânico. Diante desta manifestação, foi elaborado um cronograma de atualização dos professores. 


\section{Uma ação educativa para resolução do problema: resultados e discussão}

De acordo com os pressupostos da pesquisa-ação, os pesquisadores acadêmicos devem ter disponibilidade, cooperação e envolvimento, sendo necessário tecer a parceria e construir um clima grupal que permita a emergência qualitativa de ações em todos os participantes. Devem, ainda, estar disponíveis para participar de todas as etapas da pesquisa cuja dinâmica requer habilidade para lidar com situações não previstas. Cabe ressaltar que fomos surpreendidos com uma "situação não prevista", que foi a solicitação de atividades de atualização para os professores, mas sentimo-nos gratificados em retornar, para a sociedade, o conhecimento gerado pela Instituição, e vislumbramos como um excelente caminho para alcançarmos os objetivos pretendidos.

Atendendo a solicitação dos professores, foi realizado um curso de atualização, no período de setembro a novembro, totalizando trinta horas. O curso foi composto de três oficinas (terrário, germinação, herborização), duas visitas ao Jardim Botânico e oito encontros onde foram abordados os seguintes temas: história dos jardins botânicos e do PEFI; importância da conservação da biodiversidade, com ênfase no bioma da Mata Atlântica; plantas em extinção; preservação dos recursos hídricos, e os problemas ambientais do entorno do Parque.

As oficinas, realizadas no laboratório da escola, caracterizaram-se como momentos informais de fazer e aprender com intensa troca de experiências, socialização do conhecimento e vivências pessoais. Os pesquisadores acadêmicos traziam para o grupo o conhecimento técnico-científico, e os professores, as informações coletadas junto aos alunos, a realidade do entorno da escola e a abordagem conceitual do tema nos livros didáticos. Os docentes declararam que foi uma oportunidade significativa e única para superarem as dificuldades advindas da formação inicial, reconhecendo que jamais tiveram essa vivência prática, considerada fundamental para a motivação e a melhoria da prática pedagógica. Para cada oficina foi produzida uma apostila para auxiliar os professores na abordagem dos assuntos.

"Eu e muitos colegas que estão aqui nos formamos há 15-20 até 25 anos atrás e depois disso nunca mais freqüentamos cursos para atualizar os conbecimentos. Existem assuntos nos livros que temos dificuldade em ensinar por que no nosso tempo não se falava sobre eles." (Depoimento da professora da $2^{\mathrm{a}}$ série)

Percebemos que as práticas e reflexões propiciadas com o desenvolvimento do projeto estimularam a construção de ações para sensibilizar os alunos da importância da preservação da biodiversidade. Os professores, munidos de conhecimento e material didático-pedagógico (produzido no período de atualização e diversos livros doados pelo Jardim Botânico), decidiram criar subprojetos temáticos para desenvolverem em cada série. Dessa forma, estabeleceram-se os seguintes subprojetos: $1^{\mathrm{a}}$ série - água; $2^{\mathrm{a}}$ série - germinação; $3^{\mathrm{a}}$ série - plantas em extinção; $4^{a}$ série - terrário, tendo o PEFI e o Jardim Botânico como tema irradiador dos subprojetos. A partir de então, cada professor passou a ser um divulgador do PEFI e Jardim Botânico junto à comunidade escolar (resolução do problema).

Esse caminho escolhido pelos professores corrobora a afirmação de Leme (2006) de que os conhecimentos produzidos a partir da vivência têm um significado muito maior para os docentes e, consequentemente, chances mais concretas de desencadearem ações práticas. Cada 
A pesquisa-ação em educação ambiental...

docente, com sua formação, experiência profissional e sua história de vida, traz consigo uma rica bagagem que contribui para reflexão, construção do conhecimento e aprimoramento dos saberes consolidados.

Para subsidiar os subprojetos, foi realizada uma visita monitorada ao Jardim Botânico com os alunos, professores e alguns pais. Durante a visita, conheceram diversas espécies vegetais, as estufas, o Museu Botânico e percorreram um trecho de Mata Atlântica até chegar à Nascente do Riacho do Ipiranga, onde foi abordada a parte histórica da área e a importância da conservação dos recursos hídricos.

No decorrer dos meses de trabalho, os pesquisadores acadêmicos perceberam a integração da equipe, formando, assim, um grupo único, coeso e estimulado a superar as dificuldades, a enfrentar desafios e, até mesmo, ousar na prática pedagógica com mais segurança (acompanhamento das decisões e ações). A aquisição de conhecimentos pautados na realidade socioambiental da região estimulou os professores a estabelecerem mudanças em suas práticas profissionais a fim de atingirem os objetivos coletivamente desejados.

A qualidade dos subprojetos resultou em uma exposição dos trabalhos realizados por alunos e professores, intitulada "Vivenciando Valores na Educação em parceria com o Jardim Botânico". Esta exposição, realizada no último dia letivo, foi aberta à comunidade e contou com a presença de aproximadamente mil e quinhentas pessoas, entre pais, parentes e amigos dos estudantes, representantes do Rotary Clube, da Diretoria de Ensino Centro-Sul da capital e a equipe do JBSP. Esse foi o momento de sensibilizar além dos muros. A comunidade teve a oportunidade de conhecer o trabalho desenvolvido por alunos, professores e pesquisadores, conhecendo, assim, a importância do PEFI e do JBSP para a região.

Durante o evento, foram coletados depoimentos de alguns pais:

"Gostei da iniciativa, serviu pra conscientizar as crianças sobre a importância da água e da vegetação para todos os habitantes deste planeta chamado Terra". L.C. C. pai da aluna Natália (1ª série)

"A organização está de parabéns pelo evento. É muito gratificante saber que estão levando esse tipo de ensino a nossas crianças. Ótimo saber que essa geração se preocupa com a natureza em geral. A todos organizadores, muito obrigado pela oportunidade”. R.F. pai do aluno Marcelo ( $3^{\mathrm{a}}$ série)

"Achei muito legal esse tipo de trabalho na escola e que as crianças se interessam e se preocupam com a natureza. Gostei muito das informações dada pelos alunos, pois estes conseguiram passar de uma ótima forma”. A.B. mãe de Mireli ( $4^{a}$ série)

No final do projeto, foi aplicado um questionário aos professores, e 81\% apontaram que o enriquecimento pedagógico foi um grande benefício para a atuação profissional e que sentem-se capacitados a continuar trabalhando temas relacionados ao PEFI. Constatou-se, também, que $92 \%$ dos alunos tiveram melhor comportamento e maior participação nas atividades escolares - fator atribuído ao dinamismo das aulas e ao estudo da realidade local.

O projeto integrou o Jardim Botânico e a Escola, divulgou a função e a importância da preservação desta área de Mata Atlântica e contribuiu para a melhoria da qualidade do ensino público.

Finalizando, destacamos o depoimento de uma professora: 
Cerati, T. M.; Lazarini, R. A. M.

"A parceria com os biólogos do Jardim Botânico enriqueceu nossa estratégia em sala de aula e os alunos contextualizaram o aprendizado da escola com o mundo que o cerca".

\section{Conclusão}

Aceitamos o desafio de trabalhar com a educação formal numa intervenção educacional baseada em valores voltados à dimensão ecológica, ambiental e social.

A metodologia utilizada permitiu a implantação de um processo coletivo de produção e compartilhamento de saberes, articulado a uma ação educativa interdisciplinar que envolveu toda a comunidade escolar, possibilitando: a) o aperfeiçoamento profissional dos professores com a atualização de conteúdos pedagógicos relacionados ao meio ambiente; b) organização e reorganização do trabalho dos professores priorizando sua prática pedagógica; c) mudança no horizonte educativo dos professores, estimulando ações e reflexões que conduziram a superação de dificuldades advindas da formação inicial.

Não podemos desconsiderar que trabalhos desta natureza esbarram na atual estrutura escolar, e que o sucesso deste projeto foi possível graças à relação de confiança estabelecida entre a direção escolar e pesquisadores acadêmicos e, sobretudo, o envolvimento dos professores. Atualmente, três anos após o término do projeto, observamos o aumento do nível de consciência nas instituições envolvidas. A escola inseriu a visita ao JBSP no calendário escolar e, nas visitas realizadas nos anos posteriores, percebemos que alunos, professores e pais desenvolveram um sentimento de respeito e admiração pelo JB/PEFI e pelo trabalho empreendido para a conservação da biodiversidade. O JBSP apoiou e desenvolveu novos projetos direcionados à comunidade do entorno.

Ressaltamos a importância de se estabelecerem políticas públicas que fomentem a parceria entre instituições produtoras de saber e a educação formal a fim de promover: a divulgação do conhecimento, atualização de professores, a melhoria da qualidade do ensino e a conscientização da população sobre a importância da conservação da biodiversidade paulista e brasileira. 
A pesquisa-ação em educação ambiental...

\section{Referências}

ARAÚJO, D. Análise de um curso de formação de docente utilizando as trilhas do Jardim Botânico de Porto Alegre/RS como espaço educador. 2006. 145f. Dissertação (Mestrado em Ensino de Ciências e Matemática) - Universidade Luterana do Brasil, Porto Alegre, 2006.

BICUDO, D. C.; FORTI, M. C.; BICUDO, C. E. M. (Orgs.). Parque Estadual das Fontes do Ipiranga (PEFI): unidade de conservação que resiste à urbanização de São Paulo. São Paulo: Secretaria do Meio Ambiente do Estado de São Paulo, 2002.

DE FIORI, A. Ambiente e educação: abordagens metodológicas da percepção ambiental voltada às unidades de conservação. 2002. 111f. Dissertação (Mestrado em Ecologia e Recursos Naturais) - Centro de Ciências Biológicas e Saúde, Universidade Federal de São Carlos, São Carlos, 2002.

GONZALES, L. T. V.; TOZONI-REIS, M. F. C.; DINIZ, R. E. S. Educação ambiental na comunidade: uma proposta de pesquisa-ação. Revista Eletrônica Mestrado em

Educação Ambiental, Rio Grande, v. 18, 2007. Disponível em <http:// www.remea.furg.br/edicoes/vol18/art31v18a27.pdf>. Acesso em: 21 abr. 2008.

LEME, T. N. Os conhecimentos práticos dos professores: (re)abrindo caminhos para a educação ambiental na escola. São Paulo: Annablume, 2006.

MAROTI, P. S. Educação e interpretação ambiental junto à comunidade do entorno de uma unidade de conservação. 2002. 145f. Tese (Doutorado em Ecologia e Recursos Naturais) - Centro de Ciências Biológicas e Saúde, Universidade Federal de São Carlos, São Carlos, 2002.

PEREIRA, T. S.; COSTA, M. L. M. N.; JACKSON, P. W. (Orgs.). Plano de ação para os jardins botânicos brasileiros. Rio de Janeiro: Rede Brasileira de Jardins Botânicos, 2004.

REIS, L. A. M. Resíduos sólidos e líquidos encontrados no PEFI. In: BICUDO, D. C.; FORTI, M. C.; BICUDO, C. E. M. (Orgs.). Parque Estadual das Fontes do Ipiranga (PEFI): unidade de conservação que resiste à urbanização de São Paulo. São Paulo: Secretaria do Meio Ambiente do Estado de São Paulo, 2002. p. 259-70.

SÃO PAULO. Instituto Florestal. Reserva da Biosfera do cinturão verde da cidade de São Paulo. São Paulo: Secretaria de Estado do Meio Ambiente, 2002. 1 cd-rom (revisado em setembro de 2003).

SATO, M. Educação para o ambiente amazônico. 1997. 243f. Tese (Doutorado em Ecologia e Recursos Naturais) - Centro de Ciências Biológicas e Saúde, Universidade Federal de São Carlos, São Carlos, 1997.

SILVA, J. M. C.; JUNQUEIRA, V. Educação e conservação da biodiversidade: uma escolha. In: JUNQUEIRA, V.; NEIMAN, Z. (Orgs.). Educação ambiental e conservação da biodiversidade: reflexões e experiências brasileiras. Barueri: Manole, 2007. p. 35-48. 
Cerati, T. M.; Lazarini, R. A. M.

TABANEZ, M. F.; PÁDUA, S. M.; SOUZA, M. G. Avaliação de trilhas interpretativas para educação ambiental. In: PÁDUA, S. M.; TABANEZ, M. F. Educação ambiental: caminhos trilhados no Brasil. Brasília: IPE, 1997.

THIOLLENT, M. Metodologia da pesquisa-ação. 14. ed. São Paulo: Cortez, 2005.

TOZONI-REIS, M. F. C. Pesquisa-ação: compartilhando saberes. Pesquisa e ação educativa ambiental. In: FERRARO JR., L.A. (Org.). Encontros e caminhos: formação de educadoras (es) ambientais e coletivo educadores. Brasília: Ministério do Meio Ambiente, 2005. Disponível em: <http://mma.gov.br/port/sdi/ea/og/pog/arqs/encontros.pdf.> Acesso em: 12 abr. 2008.

WILLISON, J. Educação ambiental em jardins botânicos: diretrizes para o desenvolvimento das estratégias individuais. Rio de Janeiro: Rede Brasileira de Jardins Botânicos, 2003.

Artigo recebido em novembro de 2008 e aceito em agosto de 2009. 